\title{
Why NERICA is a successful innovation for African farmers
}

\section{A response to Orr et al from the Africa Rice Center}

\author{
M.C.S. Wopereis, A. Diagne, J. Rodenburg, \\ M. Sié and E.A. Somado
}

This paper responds to 'Funding international agricultural research and the need to be noticed: a case study of NERICA rice' by Stuart Orr, James Sumberg, Olaf Erenstein and Andreas Oswald, published in this issue of Outlook on Agriculture.

Keywords: rice; agricultural research; Sub-Saharan Africa; NERICA; WARDA

The authors are with the Africa Rice Center (WARDA), 01 BP 2031 Cotonou, Benin. E-mail: m.wopereis@cgiar.org.

\section{General comments \\ In their paper 'Funding international agricultural research and the need to be noticed: a case study of NERICA rice', Stuart Orr, James Sumberg, Olaf Erenstein and Andreas Oswald (subsequently referred to as Orr et al) blame the Africa Research Center (WARDA) for not providing scientific evidence for statements on the performance of varieties of the New Rice for Africa (NERICA). Along the way, they question both the scientific credibility and the integrity of WARDA and its staff. They argue that WARDA created interest and excitement around these varieties for the sole purpose of augmenting funding and to get the Center through difficult situations, such as the forced displacement from Côte d'Ivoire because of the civil war, and they maintain that donors blindly went along with this because of some perceived need for an African success story. WARDA is presented as a flawed institution, poorly monitored, hungry for a success story and resources, continuously fighting for survival and misleading its investors, independent reviewers and the international community regarding one of its major achievements - the NERICA varieties. WARDA scientists are depicted as uncritical, lacking objectivity and at best sloppy in the conduct and analysis of trials or in reporting the results. WARDA donors and supporters and external}

and independent reviewers appointed by donors, the CGIAR or WARDA, who have reviewed WARDA-related and NERICA-related work throughout the years, are depicted as either naive or lacking the necessary knowledge and expertise to conduct such reviews.

This type of assessment - coming from four authors not currently conducting research on rice and based outside Africa - gives an extremely distorted view of the reality, and is insulting to WARDA staff and partners who have worked and are still working, often under difficult circumstances, for the benefit of rice farmers and consumers in Sub-Saharan Africa. When deciding to paint such a negative picture of WARDA, its staff and supporters and reviewers of WARDA research, the authors should have had the intellectual honesty to inform readers that at least three of them are not disinterested parties in this assessment, having had previous employment and capacities at WARDA. ${ }^{1}$ Such information would allow readers to put their paper and its content into its proper context and judge its objectivity and merits.

Most of the claims regarding the performance of the NERICA varieties cited by the authors refer to documents published in 2003 or earlier. That is because the core of this paper is based on an unpublished draft paper entitled 'What is said and what is known about 
NERICAs' authored by ... WARDA (2003). ${ }^{2}$ This original WARDA paper was the main output of the so-called 'NERICA Claims Study Group' composed of J. Sumberg, A. Diagne, O. Erenstein, and A. Oswald. This group of WARDA scientists was formed by J. Sumberg in 2003 in Bamako (Mali) when he was WARDA's Interim Director for Research, with the responsibility for documenting all the claims made about NERICA varieties, finding gaps in the scientific evidence and making recommendations to WARDA management and staff regarding the research needed to fill any gaps in the data and to underpin public awareness messages.

Within the group, A. Diagne (a co-author of this response) was given the task of compiling all the claims presented in WARDA public documents. For that purpose, he did a literature search and developed a spreadsheet containing the claims found (46 in total) and the reference documents. This spreadsheet is the source of most of the claims analysed in the original paper, which was presented and debated during the November 2003 WARDA Research Days, following further input from a number of WARDA staff not in the 'NERICA Claims Study Group'. As a matter of ethics and scientific practice, the authors should have, at the very minimum, acknowledged the original unpublished draft WARDA internal paper from which they draw heavily.

The authors used the internal WARDA document and conducted a set of Internet searches in 2006 and 2007 to judge progress made by WARDA and partners in the evaluation of performance of NERICA varieties. They then combined this information to speculate about 'forces that result in a generally uncritical approach to the claims made about some agricultural technology'. Referring to NERICA, the authors claim to have 'found no published work that seriously interrogates the claims made about the varieties', apart from the studies conducted by Kijima et al (2005 and 2008). The Internet searches conducted by the authors appear to have missed the comprehensive review by Kaneda (2007a, b, c and d). Readers interested in a scientific, independent and objective assessment of the characteristics and performance of both upland and lowland NERICA varieties are referred to these studies. Other important reviews missed by the Internet search are Sié et al (2008) and the recent NERICA compendium jointly published by WARDA and FAO (Somado et al, 2008).

WARDA staff and partners have not made claims about NERICA without evidence. It is true that some of the evidence is 'anecdotal' (in the form of accounts of performance of NERICA varieties gathered in the fields from talking to farmers and visiting their fields, or from national agricultural research systems (NARS) and NGO collaborators and partners who are conducting NERICA trials and working with farmers). However, many of the claims quoted in the paper have been taken out of context. For example, the claim regarding the ability of NERICA varieties to increase yield significantly under both low and high input conditions, quoted in the paper in several places and in different forms, appeared originally in one WARDA publication as:

\footnotetext{
“ "In farmers' fields in Guinea, the NERICAs are yielding as high as 2.5 tonnes per hectare with few inputs. A few
}

farmers are harvesting 5 tonnes or more with just minimum increase in fertilizer use," Jones says. "We're talking about $25 \%$ to $250 \%$ production increases."'

People familiar with rice in West Africa, especially those who have been in the field visiting and talking to farmers, know that these figures reported by Jones are possible (see, for example, New York Times, 2007).

It is fair enough to fault some WARDA staff and partners for having made certain claims about the performance of NERICA varieties based on anecdotal evidence that has not been confirmed by rigorous scientific testing, or for naively attributing the observed reduction in rice imports in Guinea to the adoption of NERICA, but to jump from that to the accusation that WARDA scientists, managers and supporters are making baseless claims to mislead donors and the international community intentionally for the sole purpose of attracting donor funding, is a grave accusation. As the authors themselves acknowledge, the reporting of anecdotal evidence on new agricultural technologies is common practice.

If the hypothesis of the study is that in some cases research institutes and donors are forced to 'create interest and excitement' and 'use an uncritical approach', the authors should at the very least have conducted interviews with the various communities involved (farmers, researchers, extension officers, donors) to verify whether that had been the case in the development of NERICA varieties. They should also have consulted the independent reviews conducted since 1997 on the development and performance of NERICA varieties, and especially the External Program Management Reviews (EPMR) conducted in 2000 and 2007 on WARDA itself at the request of the Consultative Group on International Agricultural Research (CGIAR). Instead, they rely on their apparently personal experiences, used in the discussion section, when they state that the successful promotion could partly be explained by 'a number of strong and charismatic personalities'. Not only is that a subjective observation, but they also fail to indicate sources and evidence for this claim. These 'strong and charismatic personalities', together with many persons at WARDA and elsewhere known to have been associated with NERICA varieties, are readily available to be interviewed. In fact, almost all the independent reviews of WARDA and the NERICA work conducted recently have followed this course, as standard practice dictates. Thus, scientifically, the approach used by the authors is highly questionable.

After 2002, WARDA suffered a number of relocations because of the civil war in Côte d'Ivoire. This major conflict cannot be seen just as 'an additional problem', as the authors put it: in fact, it had a significant negative impact on WARDA's resources and research programme. As an illustration, all three of Orr's co-authors left WARDA at that time, and they were not the only senior scientists to leave. Many lab experiments and field tests were abruptly interrupted and valuable research data (many related to NERICA varieties) were lost indefinitely. However, despite all these interruptions and the loss of data, the forced relocations between 2002 and 2005 - not to mention the personal hardship endured by WARDA 
staff - WARDA's rice breeding research continued, and 10 more NERICA varieties were released for upland growing conditions, taking the total to 18 . A further 60 varieties were produced for lowland conditions. Both these major achievements were left out of the discussion by the authors. WARDA is currently continuing to broaden the genetic diversity of improved varieties of rice for African conditions, through both intra- and interspecific crosses.

\section{Terminology}

The section in the paper on terminology for NERICA is both confusing and out of date. The trademarked name 'NERICA' is still strictly used to indicate interspecific hybrids from crosses between O. glaberrima and O. sativa. National research institutions may request breeder or foundation seed of NERICA varieties or other improved 'lines' from WARDA and test these under farm conditions. If some of these 'lines' show good performance, they may be released in the country concerned as a new 'variety', often under a locally chosen name. The example of NERICA1, known in Côte d'Ivoire as 'Bonfani', is a good illustration of ownership by endusers of adapted technologies. ${ }^{3}$ Countries that are enlisted later do not test 'lines', but varieties already released elsewhere. All upland NERICA varieties have individual passport data and have been characterized up to the molecular level. They can, therefore, be distinguished easily (Ndjiondjop et al, 2008; Semagn et al, 2006).

Orr et al argue that in performance assessments of different NERICA varieties, all individually observed traits are generally assigned to one common variety, suggesting that all NERICA varieties or interspecifics contain all the desirable traits. WARDA scientists are depicted as either not knowing how to analyse and report the results of trials, or as trying to mislead the scientific community by creating 'the impression that all the desirable traits were combined in one line or variety'. This is a serious accusation and yet the authors do not make reference to any appropriate scientific publication. We challenge the authors to cite a single WARDA scientific publication in which the NERICA lines being tested are not clearly identified in both the analysis and the reporting of the results. In fact, in most scientific publications, the varying performances of the different NERICA lines under different stresses are emphasized. Somado et al (2008) shed further light on the term 'NERICA' as an extended family of thousands of lines, and warn about the large variation that subsequently exists among NERICA varieties, suggesting that the agro-physiological traits of NERICA cannot be generalized. Secondary references of results in publications may use the generic NERICA name without mentioning a specific line. This had already been observed and corrected by WARDA scientists (for example, Rodenburg et al, 2006).

\section{Performance of NERICA varieties}

Orr et al have decided to focus on three claims out of the dozens of claims analysed in the original WARDA paper. Rodenburg et al (2006) reported 47 scientific publications on NERICA varieties. These publications include testing of NERICA varieties against 'best' check varieties for different abiotic and biotic stresses and development of best-bet crop management practices.

Orr et al claim that there is no evidence of NERICA varieties being (a) generally higher yielding than sativas; (b) higher yielding than sativas at very low fertilizer rates; (c) significantly more responsive than sativas to fertilizer; or (d) more yield-stable than sativas. However, hundreds of lines of NERICA were tested over a number of years in the 1990s at six key sites in Côte d'Ivoire across agroecological zones at both low and high fertilizer input levels (WARDA, 1994, 1995 and 1996). The NERICA varieties that were ultimately selected from those tests systematically outperformed their sativa parents and sativa checks at both low and high input levels across sites. This means that NERICA varieties were specifically selected to do well in both low and high input environments.

The sativa parents of the NERICA lines are WARDA improved varieties known to have relatively good yield potential and good tolerance/resistance to many stresses found in farmers' fields. It is, therefore, natural to compare the performance of NERICA lines with those of their sativa and glaberrima parents. ${ }^{4}$

Orr et al completely ignore the importance of farmers in the selection process, and stress only the importance of scientific evidence in terms of yield performance. WARDA is acutely aware of the need to explain on-farm varietal performance. Testing of improved varieties and local checks are conducted independently by the African national agricultural research systems (NARS) through the various networks hosted by WARDA, with full farmer involvement. Through participatory varietal selection (PVS), farmers identify varieties they would like to adopt from an initial set of 60 or more entries (depending on the ecology, at least 20 of these entries are generally not NERICA varieties), including locally cultivated landraces and improved varieties (Gridley et al, 2002). Varieties selected by farmers are, therefore, always better (not necessarily in terms of yield) than the ones normally grown (which, in principle, can be taken as the 'best varieties' - sativa or glaberrima - in farmers' fields).

Through this PVS work, farmers in WARDA's member countries and beyond have been able to evaluate NERICA varieties, and they have subsequently chosen to adopt them in increasing numbers. In almost all cases, the set of NERICA varieties adopted or released differs from country to country. For example, in Côte d'Ivoire and Nigeria, NERICA1 and 2 are the most popular with farmers; in Guinea, NERICA1 and 6 are preferred, and NERICA4 is preferred in both Mali and Uganda (Somado et al, 2008).

Farmers cite many reasons for adopting NERICA varieties: for example, their relatively short growth duration while maintaining good yield capability. Because of their short duration of growth, NERICA varieties are used by farmers to complement traditional varieties and thus enhance the varietal diversity of rice (Barry et al, 2008). In a context of widespread malnutrition and where rice is a major staple food, it is important to note that some of the NERICA varieties have on average $25 \%$ higher protein content and exhibit a better balance of amino acids as compared with both 
imported varieties and the international rice standard (Futakuchi et al, 2008; Watanabe et al, 2002a and b).

WARDA is currently analysing the results of a large number of PVS trials across four countries to get a better understanding of the reasons for farmer adoption. We counted and documented 47 farmer criteria used to select a variety; and yield was only one of them. Moreover, an important finding in a study by Dalton (2004) of the influence of rice varietal attributes on farmer varietal choice was that yield was not a significant determinant of farmer willingness to pay for seed of different varieties. Instead, two production attributes - cycle length and plant height - and three consumption traits colour, swelling capacity and tenderness - were found to be significant determinants of farmer willingness to pay for seed of the different varieties. The study conducted in the context of the WARDA PVS trials included NERICA varieties and other improved and traditional varieties.

Despite Orr et al's assertions, the African Rice Initiative (ARI) is not a mechanism to 'push' NERICA varieties. Farmers chose NERICA varieties themselves and are perfectly free to select any other variety through the PVS mechanism employed by ARI and its partners.

\section{Weed competitiveness}

Claims concerning the weed competitiveness of NERICA varieties are based on the original idea of combining the high yield potentials of $O$. sativa with the superior weedsuppressive abilities of $O$. glaberrima. The rice type WARDA scientists had in mind while making the crosses for the upland interspecifics was one that would have rapid early growth with a high number of thin (high specific leaf area, SLA) and droopy leaves with high extinction coefficients in the vegetative phase (resembling O. glaberrima) and erect leaves and thick (low SLA) leaves and high levels of chlorophyll during the reproductive stage (resembling O. sativa) (Dingkuhn et al, 1999; Jones et al, 1997a, 1997b). Such an ideotype would smother weeds during the critical early growth stages and ensure maximum light-use efficiency during the rice grain-filling stages. Some offspring of the interspecific crosses have indeed inherited traits associated with the competitiveness of their O. glaberrima parent (Dingkuhn et al, 1999; Johnson et al, 1998; Sarla and Swamy, 2005), such as superior seedling vigour and above-ground biomass accumulation, ensuring rapid ground cover (Jones et al, 1997a). However, it has also been concluded that although many of the currently available NERICAs have relatively high yield potentials and overall adaptation, they are not as weed-competitive as their O. glaberrima parent (Dingkuhn et al, 2006). This does not exclude the likelihood of some of the NERICA varieties being more weed-competitive than locally adapted popular varieties.

Orr et al try to convince the reader that NERICA varieties are not weed-competitive by using data derived from Dingkuhn et al (1999). This, however, is not a fair comparison. The objective of the paper by Dingkuhn et al was to identify morphological characteristics of rice that could be predictive of weed competitiveness, rather than to screen for the most weed-competitive line or variety. Accordingly, the interspecifics featured in this study were 'selected from breeders' trials for morphological diversity' and not primarily for their assumed weed competitiveness. Moreover, none of the interspecifics used in this trial actually reached the nomination of upland NERICA varieties.

In our review on the achievements and impact of NERICA varieties (Rodenburg et al, 2006), we were still unable to present a comprehensive data set on the weed competitiveness of these varieties. Instead we presented preliminary results of trials in which only three NERICA varieties (notably 1, 2 and 7) were used, along with outcomes of other trials that included some interspecific lowland lines (which have not been named NERICA). Despite the small sample sizes compared with the total population of interspecifics and NERICA varieties, we were able to identify known weed-competitive morphological traits comparable with their O. glaberrima parent (CG14). This led us to the conclusion that some interspecific rice varieties inherited the weed competitiveness traits and hence that the yield advantage over their parents, observed in some of the varieties or lines, was likely to be the result of a combination of weed competitiveness and other traits.

It is true, as Orr et al state, that there is as yet insufficient scientific evidence for yield gains from both upland and lowland NERICA varieties under weedy growth conditions. WARDA and NARS scientists are, however, currently testing all named NERICA varieties (both upland and lowland) for weed competitiveness compared with their parents and some adapted, common or competitive checks in multi-season and multi-location trials. The delay between the release of the NERICA varieties (in 2000 for the first generation of upland varieties, and 2005 for the first lowland varieties) and the start of the first comprehensive testing of the weed competitiveness 'claim' (2006 for the lowland varieties, and 2007 for the upland varieties) can partially be explained (again) by the unrest in Côte d'Ivoire and the two successive moves, causing, or at least coinciding with, a high staff turnover rate. This can be illustrated with the arrival and departure dates of the scientists primarily responsible for analysing rice weed competitiveness (that is, the weed scientists and cropping systems agronomists). Collaborative weed scientists David Johnson and Rebecca Kent left in 2000 and 2001 respectively. They were not directly replaced. Cropping Systems Agronomist Andreas Oswald (a co-author of Orr) joined in 2001, and his terms of reference included the challenge of testing NERICA varieties for weed competitiveness. But as far as we know, no publication was produced out of his work on weed competitiveness (WARDA, 2005). His replacement, Robert Carsky, tragically died during the civil unrest in Côte d'Ivoire in 2004 only six months after he joined WARDA. It was only in 2007 that WARDA appointed a new weed scientist (a co-author of this response) who now works with partners from national agricultural research institutions to screen for weed-competitive abilities in rice.

Preliminary results from the study on lowland NERICA varieties show that these varieties frequently have higher tiller numbers than both their parents, but are generally of shorter stature than their O. glaberrima parent (TOG5681). Some NERICA varieties were shown to be equally weed-suppressive as the O. glaberrima 
parent and the weed-competitive check (Jaya), and had yields similar to the competitive check variety under weedy conditions (Rodenburg et al, forthcoming). Also noteworthy is that WARDA collaborates with the University of Sheffield and Wageningen University in screening all upland NERICA varieties, as well as a mapping population of the interspecific crosses of CG14 $\times$ WAB56104 for Striga spp. resistance. One interspecific (WAB951-1, progeny of NERICA7 $\times$ IR49255-B-B-5-2) has already been identified as being resistant to Striga spp. (Johnson et al, 2000).

Orr et al again state that there are no publicly available data that demonstrate that interspecifics or NERICAs are 'generally or consistently more weed-competitive than locally adapted sativa varieties'. This is not true. Haefele et al (2004) studied the weed competitiveness of 20 advanced interspecifics and five $O$. sativa varieties, including competitive (Jaya) and locally adapted (Sahel 108) ones. This trial included five early versions of later released lowland NERICA varieties. Based on their weedinflicted yield losses, four out of five of these lines outperformed the locally adapted Sahel 108 in the wet season (in the Senegal River Valley) and one of them also outperformed the weed-competitive check, Jaya. In the subsequent dry season, all five interspecifics

outperformed Sahel 108 (with a minimum margin of $12 \%$ ).

We disagree with the authors' conclusion that the weed competitiveness aimed for at the onset of the NERICA development programme was not observed in the final product. Based on the theoretical background provided by Jones et al (1997a,b) and Dingkuhn et al (1999), combined with the above-mentioned published results and preliminary observations from ongoing work, we are confident that a number of NERICA varieties (both upland and lowland) have superior weed competitiveness compared with locally adapted varieties.

\section{Adoption and impact of NERICA varieties}

The best estimate we currently have is that about 200,000 hectares of upland areas in Sub-Saharan Africa cultivated NERICA varieties in 2006 - mainly NERICA1, NERICA2, NERICA4 and NERICA10 (Somado et al, 2008). The area estimate is derived from information received from NARS and from collaborating NGOs, which in many cases used estimates from their national statistics offices or project monitoring and evaluation units. WARDA and its NARS collaborators have also conducted surveys in Guinea (2003) and Benin (2004) to estimate the area under NERICA in these two countries, arriving at 51,000 and 5,000 hectares respectively (Diagne et al, 2006; Adégbola et $a l, 2006)$. The figures for the area under NERICA varieties in Sub-Saharan Africa can only be obtained reliably through agricultural census or nationally representative surveys in all the countries where NERICA is cultivated. WARDA does not have the capacity or resources to conduct such investigations, which are, in any case, better implemented by agricultural statistical services.

With this in mind, and following a recommendation of the 2007 WARDA External Program and Management Review (EPMR), a workshop was convened by WARDA in December 2007 that brought together NARS economists and experts in the Agricultural Statistical Services of 11 of the 22 WARDA member states. They discussed ways in which information on the area under NERICA and other improved varieties and rice technologies could be collected through the existing national agricultural censuses and annual crop surveys. Consultations are currently under way in WARDA member countries to implement the recommendations of the workshop. Besides the impact studies carried out in Uganda by Kijima et al (2006 and 2008), the WARDA Impact Assessment Unit is assisting NARS to conduct adoption and impact studies, and these are currently being implemented in eight countries. Thus estimates on the adoption and impact of NERICA varieties (including impact on yield and income) are now available for Côte d'Ivoire, Guinea, Benin and The Gambia. The results show a relatively high sample adoption rate in terms of numbers of farmers in The Gambia (40\%), Guinea (23\%) and Benin (18\%). The results also show the effects of adoption of NERICA varieties on farmers' yields to be heterogeneous, but with a significantly positive mean impact for all farmers in Benin (+710 kg/ha), Guinea (+492 $\mathrm{kg} / \mathrm{ha})$ and The Gambia (+131 kg/ha), but not in Côte d'Ivoire. The mean impact for women farmers was significant in all four countries (including Côte d'Ivoire) and significantly higher than for men. Papers containing these adoption and impact estimates have been presented at international conferences and some have been published in refereed journals (Diagne, 2006a and b; Diagne and Demont, 2007; Rodenburg et al, 2006), while others have been submitted for publication in refereed journals (Diagne, 2007b; Diagne et al, 2007a and b; Adégbola et al, 2006; Adekambi et al, 2007a and b; Agboh-Noameshie et al, 2007).

As previously stated, WARDA estimates that there are currently about 200,000 ha of upland NERICA varieties planted annually across Sub-Saharan Africa, which means that about $6 \%$ of the upland rice-growing area is under NERICA. WARDA considers this estimate as conservative because in 2008, Nigeria alone, citing the National Food Reserve Agency (NFRA) of Nigeria, reported 186,000 hectares under NERICA1 in 2007, and Uganda, citing a report of the Statistics Office of the Ministry of Agriculture in Uganda, 35,000 ha under NERICA4. That scale of adoption in an African setting after five to 10 years can be considered to be quite a success (Brossier, 2007). With the current food crisis in Sub-Saharan Africa, adoption rates are expected to increase rapidly. For example, the government of Mali is importing 1,900 tonnes of NERICA4 certified seed from Uganda for use in the 2008 cropping season (USAID-Mali, 2008) on top of the 1,500 tonnes of NERICA4 certified seed available in the country, enough for 68,000 ha.

Seed availability and low quality of rice products resulting from suboptimal harvest and post-harvest practices are among the constraints that were identified by independent reviews, such as the Nigeria study commissioned by the Rockefeller and Gatsby Foundations (Spencer et al, 2006); the Interspecific Hybridization Project external review commissioned by UNDP; the WARDA Center-commissioned external review of the impact of NERICA varieties in Guinea (Brossier, 2007) and the 2007 External Program Management Review - EPMR (Science Council, 2007). 
Despite Orr et al's assertions, we feel that donors and centres can commission credible independent reviews by dispatching experts not related to the work or the centre into the field to talk to farmers and partners from the research and extension community and the private sector, and judge for themselves. This was exactly what was done in the case of the recent reviews cited above. The reviews of WARDA's breeding programmes included world-class breeders, among them World Food Prize Laureate Dr Gurdev Kush, who led the 2006 Centercommissioned external review on integrated genetic and natural resources management. In its commentary on the 2007 EPMR report, the Science Council of the CGIAR congratulated WARDA for maintaining momentum during a difficult period in its history. The Science Council also commended the Panel for the excellent analysis of WARDA's work on genetic improvement, and noted that it had conducted an in-depth analysis of the programme content (Science Council, 2007). Furthermore, independent scholars have conducted their own research on the performance, adoption and impact of NERICA varieties (Fujii et al, 2004; Kijima et al, 2005, 2006 and 2008).

\section{Comparison with the system of rice intensification (SRI)}

Comparison with SRI is not logical, as the early 'claims' about the performance of NERICA varieties cited by the authors were not taken from refereed journals, as was the case for SRI. Projections made on attainable yields with NERICA published in refereed journals were likewise never unrealistic, as was the case for SRI. Moreover, there is a lack of published evidence for significant adoption of SRI beyond Madagascar, whereas upland and lowland NERICA rice varieties are documented as having been adopted and/or released in over 30 countries in SubSaharan Africa.

\section{Concluding remarks}

Sub-Saharan Africa imported close to 10 million tonnes of milled rice in 2007. With current rice prices having broken all previous records and world stocks of grains, including rice, at all-time lows, food supplies for a large majority of African countries are very precarious. The only sustainable option left to threatened African countries is to boost domestic production of rice. WARDA is acutely aware that a 'green revolution' in Africa is not possible by focusing on a single variety, or even a group of related varieties (Diagne, 2006b; Seck, 2008). There are many other issues to consider, including improved access to seed, mineral fertilizer and small-scale machinery, knowledge on best-bet rice management, and harmonization of rice policies among rice-producing countries. In the medium to long term, irrigation facilities need to be developed or rehabilitated, and part of Africa's vast potential of inland valley lowlands may be developed to grow rice in the wet season and other crops in the off-season. A major effort is needed towards improving the quality of African-grown rice to compete with imports (Seck, 2008).

Investment in building human capacity to conduct rice research for development and to (re-)establish national and regional rice research and training centres is equally important. Agricultural and rice research remains severely underfunded in Sub-Saharan Africa. The development and adoption of NERICA varieties by farmers have gradually stimulated a renewed interest in rice research, which will ultimately benefit Africa's rice farmers and rice consumers.

Orr et al seem to be unaware of the content of recently obtained (2005-07) project grants related to enhancing genetic diversity and breeding at WARDA. These projects consider both intra- and interspecific crosses (including crosses with $O$. barthii) with the aim of substantially widening genetic diversity since the successful crossing of O. glaberrima and O. sativa enabled the development of the first NERICA varieties for upland conditions. The WARDA genetics programme is also working on the improvement of O. glaberrima.

Orr et al try to illustrate the general claims made about NERICA by mentioning that NERICA has been called 'miracle rice' by Harsch (2004). They fail to acknowledge, however, that WARDA scientists themselves have tried to disseminate a more balanced picture. Rodenburg et al (2006), for instance, concluded that 'no single NERICA variety combines all the useful characteristics and NERICA is no "miracle" variety'. Blaming WARDA for disseminating a more favourable image of NERICA varieties than can be proved with scientific evidence is in our opinion not correct. The NERICA varieties do generally perform well, and farmers do appreciate them. WARDA scientists are therefore generally proud and enthusiastic about this achievement, and so are the donors. Being enthusiastic is no scientific crime. At the same time, WARDA scientists are fully aware that scientific data are needed to substantiate the 'claims'. This work has been seriously delayed due to the Ivorian crisis, the resulting high staff turnover and two successive moves, but is still currently in progress. More importantly, since NERICA varieties are international public goods, anyone from outside the scientific community can make statements about them. The public domain is hard, if not impossible, to control.

Orr et al attempt to diminish the importance of the scientific achievement of the WARDA team led by M. Jones by invoking earlier work on interspecific hybridization. But they fail to mention that this earlier work by Belgian and French institutions in the 1980s did not bear fruit. The scientific achievement of the WARDA team has been widely recognized. To quote E.Q. Javier (former Chairman of the CGIAR Technical Advisory Committee) in the 2000 WARDA EPMR:

'Overcoming hybrid sterility barriers and the successful introgression of adaptation and tolerance genes from African rices (Oryza glaberrima) into the highyielding rices of Asia is a major scientific breakthrough in rice improvement. This achievement at WARDA will have a major impact on rice production not only in Africa, but also in Asia and Latin America.'

It should further be noted that the information given about WARDA in the Orr et al paper is not up to date. WARDA is an autonomous intergovernmental research- 
for-development institution of 22 member states. The 2008 budget of the Center is US\$14 million and the staff are located in Benin, Côte d'Ivoire, Nigeria, Tanzania and Senegal. More information can be found at the Website: www.warda.org.

In summary, the article by Orr et al, based on an internal WARDA document written in November 2003 and augmented with results from Internet searches, is outdated and does not seem to be fair, objective or useful. We invite the authors to visit WARDA or any of its partners in Sub-Saharan Africa for evidence of the impact of NERICA varieties or the other improved varieties and technologies that have been developed and disseminated by WARDA in recent years.

\section{Notes}

${ }^{1}$ The two versions of the paper sent to us by the editor included the names and current institutional affiliations of the authors, but did not include this information. We presume that the editor and the reviewers were not aware of this fact.

2 Two footnotes in the title of the paper read as follows: 'Prepared for WARDA Research Days 2004, 8-12 December 2003, Samako, Mali' and 'Drafted by J. Sumberg but reflecting a collaborative effort by A. Diagne, O. Erenstein, A. Oswald and others'.

3 'Bonfani' means 'good smell' in Baoulé.

${ }^{4}$ The NERICA parents were selected out of 316 improved and 275 traditional O. sativa and 1,130 O. glaberrima accessions evaluated for morphological and agronomic traits during 1991-92 (WARDA, 1995).

\section{References}

Adégbola, P. Y., Arouna, A., Diagne, A., and Souléïmane, A. A. (2006), 'Evaluation de l'impact économique des nouvelles variétés de riz NERICA au Bénin: évidence avec les modèles basés sur 1'approche contre factuel', paper presented at the first Africa Rice Congress, 31 July-4 August, Dar es Salaam, Tanzania

Adékambi, A. S., Diagne, A., and Biaou, G. (2007a), 'Impact de l'adoption des variétés NERICA sur la pauvreté des ménages au Bénin: cas du département des Collines', mimeo, INRAB, Cotonu, Benin.

Adékambi, A. S., Souléïmane, A. A., Diagne, A., and Biaou, G. (2007b), 'Impact de l'adoption des variétés NERICA sur la scolarisation des enfants au Bénin: cas du département des Collines', mimeo, INRAB, Cotonou.

Agboh-Noameshie, A. R., Kinkingninhoun-Medagbe, F. M., and Diagne, A. (2007), 'Gendered impact of NERICA adoption on farmers' production and income in central Benin', paper presented at the International Conference of the African Association of Agricultural Economists (AAAE), 20-22 August, Accra, Ghana.

Barry, M. B., Diagne, A., Pham, J. L., and Ahmadi, N. (2008), 'Recent evolution of rice genetic diversity in Guinea', Cahiers d'études et de recherches francophones/Agricultures, Vol 17, No 2, March/April.

Brossier, J. (2007), 'Evaluation of the impact of NERICA rice varieties in Guinea', WARDA, Cotonou, Benin.

Dalton, T. J. (2004), 'A household hedonic model of rice traits: economic values from farmers in West Africa', Agricultural Economics, Vol 31, pp 149-159.

Diagne, A. (2006a), 'The diffusion and adoption of NERICA rice varieties in Côte d'Ivoire', The Developing Economies, Vol 44, No 2, pp 208-231.

Diagne, A. (2006b), 'Le Nerica, myth et réalité', Grain de Sél, Special Issue 34-35, March-August.

Diagne, A. (2007a), 'In situ conservation of crop biodiversity: measurement and monitoring with applications to rice biodiversity in West Africa', paper presented at the 7th International Conference of the European Society for Ecological Economists, 5-8 June, Leipzig, Germany.

Diagne, A. (2007b), 'Bred for women rice farmers? Impact of NERICA adoption on rice yield in Côte d'Ivoire', mimeo, WARDA, Cotonou, Benin.

Diagne, A., and Demont, M. (2007), 'Taking a new look at empirical models of adoption: average treatment effect estimation of adoption rates and their determinants', Agricultural Economics, Vol 37, pp 201-210.

Diagne A., Sogbossi, M. J., Diawara, S., and Camara, A. (2006), 'L'étendu du succès de la dissémination des variétés NERICA en Guinée: estimation des superficies emblavées', mimeo, WARDA, Cotonou.

Diagne, A., Sogbossi, M. J., Kouame, P., Diawarra, S., and Sidy, M. (2007b), 'Impact of the NERICA in Guinea: productivity and income gains', mimeo, WARDA, Cotonou.

Diagne, A., Sogbossi, M. J., Sékou, D., Sadio Diallo, A., and Bacar Barry, A. (2007a), 'Evaluation de la diffusion et de l'adoption des variétés de riz NERICA en Guinée', (mimeo, ADRAO) paper presented at the AAAE 2nd Conference, 19-22 August, Accra.

Dingkuhn, M., Johnson, D. E., Sow, A., and Audebert, A. Y. (1999), 'Relationships between upland rice canopy characteristics and weed competitiveness', Field Crops Research, Vol 61, pp 79-95.

Dingkuhn, M., Singh, B. B., Clerget, B., Chantereau, J., and Sultan, B. (2006), 'Past, present and future criteria to breed crops for water-limited environments in West Africa', Agricultural Water Management, Vol 80, pp 241-261.

Fujii, M., Andoh, C., and Ishihara, S. (2004), 'Drought resistance of NERICA (New Rice of Africa) compared with Oryza sativa L. and millet evaluated by stomatal conductance and soil water content', $4^{\text {th }}$ International Crop Science Congress, 26 September-1 October, Brisbane.

Futakuchi, K., Watanabe, H., and Jones, M. P. (2008), 'Relationship of grain protein content to other grain quality traits in interspecific Oryza sativa L. x Oryza glaberrima Steud. progenies', Agricultural Journal, Vol 3, No 1, pp 50-57.

Gridley, H. E., Jones, M. P., and Wopereis-Pura, M. (2002), 'Development of New Rices for Africa (NERICA) and Participatory Varietal Selection', paper presented at a workshop on Development of the New Rice for Africa (NERICA) and Participatory Varietal Selection, March, WARDA, Bouaké, Côte d'Ivoire.

Haefele, S. M., Johnson, D. E., M’Bodj, D., Wopereis, M. C. S., and Miezan, K. M. (2004), 'Field screening of diverse rice genotypes for weed competitiveness in irrigated lowland ecosystems', Field Crops Research, Vol 88, pp 39-56.

Harsch, E. (2004), 'Farmers embrace African "miracle rice"', Africa Recovery, Website: http://www.un.org/ecosocdev/geninfo/ afrec/vol17no4/174rice.htm (accessed 30 June 2008).

Johnson, D. E., Dingkuhn, M., Jones, M. P., and Mahamane, M. C. (1998), 'The influence of rice plant type on the effect of weed competition on Oryza sativa and Oryza glaberrima', Weed Research, Vol 38, pp 207-216.

Johnson, D. E., Riches, C. R., Jones, M. P., and Kent, R. (2000), 'The potential for host resistance to striga on rice in West Africa', in Haussmann, B. I. G., et al, eds, Proceedings of the Conference on Breeding for Striga Resistance in Cereals, IITA, Ibadan, Nigeria, Margraf Verlag, Weikersheim, Germany, pp 139-146.

Jones, M. P., Dingkuhn, M., Aluko, G. K., and Semon, M. (1997a), 'Interspecific Oryza sativa L. x O. glaberrima Steud. progenies in upland rice improvement', Euphytica, Vol 94, pp 237-246.

Jones, M. P., Mande, S., and Aluko, K. (1997b), 'Diversity and potential of Oryza glaberrima Steud in upland rice breeding', Breeding Science, Vol 47, pp 395-398.

Kaneda, C. (2007a), 'Breeding and dissemination efforts of "NERICA" (1) Breeding of upland rice', Journal of Tropical Agriculture, Vol 51, No 1, pp 1-4.

Kaneda, C. (2007b), 'Breeding and dissemination efforts of "NERICA" (2) Evaluation of important characteristics', 
Journal of Tropical Agriculture, Vol 51, No 2, pp 41-45.

Kaneda, C. (2007c), 'Breeding and dissemination efforts of "NERICA" (3) Important characteristics for lowland rice', Journal of Tropical Agriculture, Vol 51, No 3, pp 79-83.

Kaneda, C. (2007d), 'Breeding and dissemination efforts of "NERICA" (4) Efforts for dissemination of NERICAs in African countries', Journal of Tropical Agriculture, Vol 51, No 4, pp 145-151.

Kijima, Y., Otsuka, K., and Sserunkuuma, D. (2006), 'Assessing the impact of a new technology on poverty reduction: the case of NERICA in Uganda', paper presented at the Mini-symposium New Technology Development to Reduce Hunger in Sub-Saharan Africa, organized for the 26th Conference of the International Association of Agricultural Economists, 12-18 August, Brisbane.

Kijima, Y., Otsuka, K., and Sserunkuuma, D. (2008), 'Assessing the impact of NERICA on income and poverty in central and western Uganda', Agricultural Economics, Vol 38, pp 327-337.

Kijima Y., Sserunkuuma, D., and Otsuka, K. (2005), 'How revolutionary is the "NERICA Revolution"? Evidence from Uganda', The Developing Economies, Vol 44, No 2, pp 252-267.

Ndjiondjop, M. N., Semagn, K., Cissoko, M., Jones, M. P., and McCouch, S. (2008), 'Molecular characterisation of NERICA lines', in Somado, E. A., Guei, R. G., and Keya, S. O., eds, The New Rice for Africa - A Compendium, Africa Rice Center, Cotonou, Benin, pp 49-61.

New York Times (2007), 'In Africa, prosperity from seeds falls short', 10 October, Website: http://www.nytimes.com/2007/10/ 10/world/africa/10rice.html (accessed 11 October 2007).

Rodenburg, J. et al (2006), 'Achievements and impact of NERICA on sustainable rice production in sub-Saharan Africa', International Rice Commission Newsletter, Vol 55, pp 45-58.

Rodenburg, J., Saito, K., Touré, A. D., and Kiepe, P. (forthcoming), 'Weed competitive abilities of the lowland NERICA rice varieties'.

Sarla, N., and Swamy, B. P. M. (2005), 'Oryza glaberrima: a source for the improvement of Oryza sativa', Current Science, Vol 89, pp 955-963.

Science Council (2007), Report of the Fifth External Program and Management (EPMR) of the Africa Rice Center (WARDA), Science Council Secretariat, CGIAR, Rome.

Seck, P. A. (2008), 'L'Afrique est l'avenir du monde pour la riziculture', Website: http://www.africanglobalnews.com/ article3660.html (accessed 8 April).

Semagn, K., Ndjiondjop, M. N., and Cissoko, C. (2006),

'Microsatellites and agronomic traits for assessing genetic relationships among 18 New Rice for Africa (NERICA) varieties', African Journal of Biotechnology, Vol 5, No 10, pp 800810.

Sié, M., et al (2008), 'Regional yield evaluation of the interspecific hybrids (O. glaberrima $\times \mathrm{O}$. sativa) and intraspecific (O. sativa x O. sativa) lowland rice', Asian Journal of Plant Sciences, Vol 7, No 2, pp 130-139.

Somado, E. A., Guei, R. G., and Keya, S. O. (2008), The New Rice for Africa - A Compendium, Africa Rice Center, Cotonou, Benin

Spencer, D., Dorward, A., Abalu, G., Philip, D., and Ogungbile, D. (2006), 'Evaluation of adoption of NERICA and other improved upland rice varieties following varietal promotion activities in Nigeria', final report, a study for the Gatsby Foundation, London, and Rockefeller Foundation, New York.

USAID-Mali (2008), 'Mali - period update on the domestic food security situation, summary situation as of June 20, 2008', USAID, Washington, DC.

WARDA (1994), Annual Report 1994, WARDA, Bouaké, Côte d'Ivoire.

WARDA (1995), Annual Report 1995, WARDA, Bouaké, Côte d'Ivoire.

WARDA (1996), Annual Report 1996, WARDA, Bouaké, Côte d'Ivoire.

WARDA (2003), 'What is said and what is known about NERICAs', draft v2, November, Africa Rice Center (WARDA), Bamako, Mali.

WARDA (2005), Program Report 2002-2003, Africa Rice Center (WARDA), Cotonou, Benin.

Watanabe, H., Futakuchi, K., Jones, M. P., Teslim, I., and Sobambo, B. A. (2002a), 'Milling characteristics and grain quality traits of interspecific progenies of Asian rice (Oriza sativa) with African rice (Oriza glaberrima)', Japanese Journal of Tropical Agriculture, Vol 46, No 1, pp 47-55.

Watanabe H., Futakuchi, K., Jone, M. P., Teslim, I., and Sobambo, B. A. (2002b), ‘Brabender Viscogram characteristics of interspecific progenies of Oriza glaberrima Steud. and O. sativa L. Nippon Shokuhin Kagaku Kaishi', Japanese Journal of Food Science and Technology, Vol 49, No 3, pp 155-165. 